\title{
Peningkatan Produksi Jintan Hitam (Nigella sativa L.) dengan Pemberian Asam Humat dan Waktu Panen Berbeda
}

\section{Production Enhancement of Black Cumin (Nigella sativa L.) with Application of Humic Acid and Harvesting Time}

\author{
Danar Hadisugelar', Ani Kurniawati", Sandra Arifin Aziz², dan Didah Nur Faridah ${ }^{3}$ \\ ${ }^{1}$ Program Studi Agronomi dan Hortikultura, Sekolah Pascasarjana, Institut Pertanian Bogor \\ ${ }^{2}$ Departemen Agronomi dan Hortikultura, Fakultas Pertanian, Institut Pertanian Bogor \\ (IPB University), Jl. Meranti, Kampus IPB Darmaga, Bogor 16680, Indonesia \\ ${ }^{3}$ Departemen Ilmu dan Teknologi Pangan, Fakultas Teknologi Pertanian, Institut Pertanian Bogor \\ (IPB University), Jl. Meranti, Kampus IPB Darmaga, Bogor 16680, Indonesia
}

Diterima 15 Maret 2020/Disetujui 22 Juli 2020

\begin{abstract}
Black cumin (habatussauda) is a herb plant that is used all over the world for treatment or prevention of diseases. Seeds and seed oil of habatussauda have many advantages. The research aimed to determine yield component and active compound of habatussauda with treatments of humic acid and harvesting time. The research was conducted at the Pasir Sarongge Experimental Station, Cianjur, West Java, Indonesia, from May to December 2019. The experiment was arranged in a randomized completely block design with two factors. The levels of humic acid treatment were $0,1.5,3$, and 4.5 ton ha ${ }^{-1}$, and harvesting time levels were 6, 7, 8, and 9 weeks after anthesis. The results showed that humic acid up to 3 ton ha ${ }^{-1}$ did not have significant effects on capsule and seed productivity, but humic acid 4.5 ton hat decreased those. Humic acid and harvesting time did not have significant effects on thymoquinone content and production. Harvesting time at 6 until 7 weeks after anthesis was the best time for harvesting capsule and seed.
\end{abstract}

Keywords: capsule, habbatussauda, seed, thymoquinone

\section{ABSTRAK}

Jintan hitam (habbatussauda) adalah tanaman yang digunakan di seluruh dunia sebagai tanaman obat untukpencegahan dan pengobatan penyakit. Biji dan minyak yang berasal dari biji adalah bagian yang sering digunakan. Penelitian ini bertujuan untuk mempelajari komponen produksi dan bahan aktif habatussauda dengan pemberian asam humat dan waktu panen berbeda. Penelitian ini dilaksanakan di Kebun Percobaan IPB Pasir Sarongge, Cianjur, Jawa Barat Indonesia pada bulan Mei sampai Desember 2019. Percobaan menggunakan rancangan acak kelompok faktorial dengan pemberian asam humat 0, 1.5, 3.0, dan 4.5 ton ha ${ }^{-1}$ sebagai faktor pertama dan waktu panen berbeda pada 6, 7, 8, dan 9 minggu setelah antesis sebagai faktor kedua. Hasil penelitian menunjukkan pemberian asam humat sampai 3 ton ha ${ }^{-1}$ tidak menunjukkan pengaruh nyata pada produksi kapsul, biji dan produktivitas, namun pemberian asam humat 4.5 ton ha ${ }^{-1}$ menurunkan produksi kapsul dan biji. Pemberian asam humat dan waktu panen tidak berpengaruh nyata terhadap kadar dan produksi timokuinon. Waktu panen terbaik adalah 7 sampai 8 minggu setelah antesis pada produksi kapsul dan biji.

Kata kunci: biji, habbatussauda, kapsul, timokuinon

\section{PENDAHULUAN}

Jintan hitam (Nigella sativa L.) merupakan tanaman dari keluarga Ranunculaceae. Tanaman ini digunakan di seluruh dunia sebagai tanaman obat untuk berbagai penyakit

\footnotetext{
* Penulis untuk korespondensi. e-mail: ani_kurniawati@apps.ipb. ac.id
}

(Ahmad et al., 2013). Bagian biji dan minyak tanaman jintan hitam secara umum digunakan untuk pengobatan berbagai penyakit dan memiiki manfaat farmaklogis seperti antioksidan, antikanker dan antitusif (Tavakkoli et al., 2017). Biji tanaman ini memiliki kandungan bahan aktif timokuinon (Gerige et al., 2009). Pengembangan tanaman ini di Indonesia masih terkendala karena faktor iklim khususnya suhu (Herlina, 2018). 
Tanaman jintan hitam mampu berproduksi 290-333 $\mathrm{kg} \mathrm{ha}^{-1}$ biji di daerah Mediterania (Rabbani et al., 2011). Produksi tanaman jintan hitam di Indonesia berdasarkan hasil penelitian pada tiga ketinggian memiliki estimasi produksi 114.13-215.46 $\mathrm{kg} \mathrm{ha}^{-1}$ untuk aksesi India, sedangkan untuk aksesi Kuwait estimasi produksi biji 273.24-717.68 $\mathrm{kg} \mathrm{ha}^{-1}$ (Herlina, 2018). Upaya peningkatan produksi biomasa dan bahan aktif jintan hitam adalah melalui perbaikan teknik budidaya, diantaranya pemberian asam humat.

Asam humat merupakan makromolekul yang mengandung zat humat dan merupakan bahan organik yang tersebar pada tanah, air, dan sedimen serta dapat digunakan untuk pertanian (De Melo et al., 2016). Materi humat mampu memicu perkembangan akar lateral dengan mendorong fase mitosis di daerah perakaran yang secara bersamaan meningkatkan kepadatan akar, sehingga mampu meningkatkan penyerapan unsur hara (Zandonadi et al., 2007). Pemberian asam humat pada tanaman jintan hitam meningkatkan pertumbuhan pada fase vegetatif dan komponen produksi (Aiyafar et al., 2015). Pemberian asam humat $3 \mathrm{~kg} \mathrm{ha}^{-1}$ meningkatkan produksi timokuinon, p-cyeme, minyak esensial, dan produksi biji jintan hitam dibandingkan dengan tanpa pemberian asam humat (Ariafar dan Forouzandeh, 2017). Waktu panen yang tepat juga berpengaruh pada produksi biji dan produksi senyawa bahan bioaktif. Tingkat kematangan panen mempengaruhi komposisi dan bobot 1,000 biji tanaman jintan hitam (Telci et al., 2014). Duda et al. (2015) dalam penelitiannya pada tanaman Agastache felinicum, Lavandula angustifolia, Melissa officinalis, dan Nepta cataria memperoleh hasil bahwa waktu panen yang berbeda berpengaruh terhadap kandungan polifenolik total, dan kandungan flavonid seperti flavone atau flavonol. Lin et al. (2014) dalam penelitiannya pada Pleurotus eryngii memperoleh hasil bahwa perbedaan waktu panen berpengaruh terhadap jumlah kandungan asam fenolik, flavonoid dan senyawa lainnya. Semakin cepat dipanen maka komposisi bahan bioaktif akan semakin tinggi.

Berdasarkan uraian di atas, maka diperlukan penelitian untuk mempelajari informasi tentang pengaruh dari asam humat dan waktu panen terhadap komponen produksi dan kandungan bahan aktif biji jintan hitam, sehingga didapatkan rekomendasi kedua spek tersebut untuk budidaya tanaman jintan hitam di Indonesia.

\section{BAHAN DAN METODE}

Penelitian ini dilaksanakan pada bulan Mei sampai Desember 2019 di kebun percobaan IPB Pasir sarongge, Cianjur, Jawa Barat pada ketinggian 1,117 m dpl dengan jenis tanah andosol. Bahan yang digunakan adalah benih jintan hitam aksesi Amerika, asam humat AH-90, urea $120 \mathrm{~kg} \mathrm{ha}^{-1}$, SP-36 $157 \mathrm{~kg} \mathrm{ha}^{-1}$, dan KCl $90 \mathrm{~kg} \mathrm{ha}^{-1}$ sebagai pupuk dasar. Pupuk kandang sapi 10 ton ha-1, arang sekam 10 ton ha ${ }^{-1}$ dan kapur 4 ton $\mathrm{ha}^{-1}$. Petak berukuran $1.2 \mathrm{~m}$ x $1.2 \mathrm{~m}$ dengan tinggi petak $20 \mathrm{~cm}$ dan jarak antar petak $50 \mathrm{~cm}$. Penentuan jumlah bakteri menggunakan metode cawan (total plate count). Pengujian kadar timokuinon menggunakan metode
Al-Saleh et al. (2006) yang dimodifikasi Al Asad (2019) dengan bahan dan alat metanol, aqua bidestila, oven dan HPLC (high performance liquid chromatography) Agilent seri 1,200 .

Penelitian ini menggunakan rancangan acak kelompok (RAK) faktorial. Faktor pertama adalah pemberian asam humat dengan empat taraf yaitu $0,1.5,3.0$, dan 4.5 ton $\mathrm{ha}^{-1}$ dan waktu panen dengan empat taraf yaitu $6,7,8$, dan 9 minggu setelah antesis (MSA) sebagai faktor kedua. Percobaan terdiri atas 16 kombinasi perlakuan dengan 3 ulangan sehingga terdapat 48 unit percobaan dan setiap unit percobaan memiliki 32 tanaman dan terdapat 6 tanaman yang diamati sehingga total tanaman adalah 1,536 tanaman. Peubah yang diamati meliputi jumlah kapsul total, jumlah kapsul isi, persentase kapsul hampa, jumlah biji per kapsul, bobot biji per tanaman, bobot 100 biji, produktivitas dan kadar serta produksi timokuinon. Data yang diperoleh dianalisis menggunakan uji $\mathrm{F}$ dengan alfa 5\%, jika perlakuan berpengaruh nyata maka dilanjutkan dengan uji DMRT (Duncan's Multiple Range Test). Pengolahan data menggunakan software STAR 2.0.1.

\section{HASIL DAN PEMBAHASAN}

\section{Kondisi Tanah dan Iklim}

Hasil analisis media tanam terdapat pada Tabel 1. Kondisi tanah awal setelah diberikan pupuk kandang, arang sekam, dan kapur memiliki $\mathrm{pH}\left(\mathrm{H}_{2} 0\right) 5.10$ dan $\mathrm{pH}$ akhir setelah diberi asam humat 6.50. Jumlah bakteri penambat $\mathrm{N}$ dan pelarut $\mathrm{P}$ dosis kontrol masing-masing mencapai $3.02 \times 10^{6}$ dan $1.1 \times 10^{3}$ sedangkan untuk dosis 3 ton ha $^{-1}$ masing-masing mencapai $6.72 \times 10^{6}$ dan $6.00 \times 10^{2}$, dengan kandungan $\mathrm{C}$ organik (\%) sangat tinggi.

Kadar $\mathrm{C}$ organik dalam tanah yang sangat tinggi mencerminkan tingkat kesuburan yang baik. Kadar Ntotal yang sedang juga berpengaruh terhadap pertumbuhan dan produksi tanaman. Kandungan $\mathrm{C} / \mathrm{N}$ ratio yang sedang mengindikasikan bahwa bahan organik dalam tanah sudah terurai dan dan hara mineral dapat diserap oleh tanaman. Selain itu, kadar $\mathrm{P}_{2} \mathrm{O}_{5}$ dan $\mathrm{K}_{2} \mathrm{O}$ tersedia dan total pada penelitian ini sangat tinggi. Kondisi iklim selama penelitian memiliki rataan suhu minimum $10.76{ }^{\circ} \mathrm{C}$, maksimum $36.76{ }^{\circ} \mathrm{C}$, rataan kelembaban $62.92 \%$, curah hujan 80.42 $\mathrm{mm}$ dan lama penyinaran $57.18 \%$. Tuncturk et al. (2012) pada wilayah Mediterania tanaman jintan hitam umumnya tumbuh pada lahan dengan $\mathrm{pH} 7.8$, curah hujan rendah 349.4-424.1 mm per tahun dan suhu antara 9-10 ${ }^{\circ} \mathrm{C}$.

Kondisi iklim dan tanah selama penelitian mendukung pertumbuhan tanaman jintan hitam sehingga dapat tumbuh dan berkembang serta menyelesaikan siklus hidupnya dengan sempurna.

\section{Produksi Kapsul dan Biji}

Pemberian asam humat berpengaruh nyata pada jumlah kapsul total dan jumlah kapsul isi, tetapi tidak berbeda nyata terhadap jumlah kapsul hampa. Pemberian 
Tabel 1. Karakteristik tanah dalam penelitian di Kebun Percobaan IPB Pasir Sarongge Kabupaten Cianjur, Jawa Barat

\begin{tabular}{llcc}
\hline Jenis analisis & \multicolumn{1}{c}{ Metode } & Kandungan & Kriteria* $^{*}$ \\
\hline C Organik (\%) & Walkey \& Black & 6.41 & Sangat tinggi \\
$\mathrm{N}$ total $(\%)$ & Kjeldhal & 0.58 & Sedang \\
$\mathrm{C} / \mathrm{N}$ Ratio & Penghitungan & 11.00 & Sedang \\
$\mathrm{P}_{2} \mathrm{O}_{5}$ tersedia $(\mathrm{ppm})$ & Bray I & 41.72 & Sangat tinggi \\
$\mathrm{P}_{2} \mathrm{O}_{5}$ total $\left(\mathrm{mg} \mathrm{100} \mathrm{g}^{-1}\right)$ & $\mathrm{HCl} \mathrm{25 \%}$ & 739.10 & Sangat tinggi \\
$\mathrm{K}_{2} \mathrm{O}$ total $\left(\mathrm{mg} \mathrm{l} \mathrm{100} \mathrm{g}^{-1}\right)$ & $\mathrm{HCl} \mathrm{25 \%}$ & 114.60 & Sangat tinggi \\
\hline
\end{tabular}

Keterangan: Hasil analisis lab. ICBB (2019), ${ }^{*}$ Kriteria hasil analisis tanah mengacu pada Balittanah (2009)

asam humat dengan dosis sampai 3 ton ha $^{-1}$ menunjukkan pengaruh yang tidak berbeda dengan kontrol terhadap jumlah kapsul total dan jumlah kapsul isi, tetapi pemberian mencapai 4.5 ton ha $^{-1}$ menurunkan jumlah kapsul total dan jumlah kapsul isi (Tabel 2). Aiyafar et al. (2015) dalam penelitiannya menjelaskan bahwa pemberian asam humat pada daun (foliar application) berpengaruh nyata terhadap jumlah kapsul pertanaman dan hasil biologi (dry matter) tanaman jintan hitam.

Waktu panen yang berbeda berpengaruh nyata terhadap jumlah kapsul total dan jumlah kapsul isi, tetapi tidak berbeda nyata terhadap persentase kapsul hampa (Tabel 2). Waktu panen 6 dan 7 MSA tidak menunjukkan berbeda nyata terhadap persentase kapsul hampa dan jumlah kapsul isi, tetapi waktu panen pada 9 MSA menurunkan jumlah kapsul total dan jumlah kapsul isi.

Jumah kapsul pada penelitian ini lebih banyak dibanding dengan penelitian sebelumnya di Indonesia yang mampu menghasilkan 26.21 kapsul (Al Asad, 2019), 13.87 kapsul (Mardisiwi et al., 2018) dan 13.20 kapsul (Setiawati et al., 2018) dengan waktu pemanenan pada tingkat kematangan sempurna. Jumlah kapsul di India mencapai 19 kapsul (Giridhar et al., 2017), Turki 7.7 kapsul (Kara et al., 2015), sedangkan di Iran 11.2 kapsul (Safaei et al., 2014). Hal ini diduga karena ketersediaan unsur hara N, P, dan K yang tinggi pada tanah (Tabel 1) sehingga meningkatkan jumlah kapsul. Ali et al. (2015) dalam penelitiannya menjelaskan bahwa hara $\mathrm{N}, \mathrm{P}$ dan $\mathrm{K}$ berpengaruh terhadap jumlah kapsul per tanaman, biji per kapsul, dan produksi biji tanaman jintan hitam.

Pemberian asam humat berpengaruh nyata pada bobot biji per tanaman dan produktivitas, tetapi tidak berbeda nyata terhadap jumlah biji per kapsul dan bobot 100 biji. Waktu panen berpengaruh nyata pada jumlah biji per kapsul, dan bobot biji per tanaman, tetapi tidak berbeda nyata pada bobot 100 biji dan produktivitas (Tabel 3). Pemberian asam humat dengan dosis sampai 3 ton $\mathrm{ha}^{-1}$ menunjukkan pengaruh yang tidak berbeda dengan kontrol terhadap bobot biji per tanaman dan produktivitas, tetapi peningkatan dosis asam humat hingga 4.5 ton ha ${ }^{-1}$ menurunkan bobot biji per tanaman dan produktivitas tanaman jintan hitam.

Tabel 2. Jumlah kapsul total, jumlah kapsul isi, dan persentase kapsul hampa pada berbagai dosis asam humat dan waktu panen berbeda pada tanaman jintan hitam

\begin{tabular}{|c|c|c|c|}
\hline Perlakuan & Jumlah kapsul total & Jumlah kapsul isi & Persentase kapsul hampa \\
\hline \multicolumn{4}{|c|}{ Asam humat (ton ha-1) } \\
\hline Kontrol & $71.9 \mathrm{a}$ & $59.1 \mathrm{a}$ & 17.78 \\
\hline 1.5 & $72.5 \mathrm{a}$ & $58.7 \mathrm{a}$ & 18.99 \\
\hline 3.0 & $81.2 \mathrm{a}$ & $68.8 \mathrm{a}$ & 15.22 \\
\hline 4.5 & $55.2 \mathrm{~b}$ & $42.8 b$ & 22.39 \\
\hline \multicolumn{4}{|c|}{ Waktu panen (MSA) } \\
\hline 6 & $79.4 \mathrm{a}$ & $64.5 \mathrm{a}$ & 18.73 \\
\hline 7 & $79.1 \mathrm{a}$ & $64.9 \mathrm{a}$ & 17.86 \\
\hline 8 & $65.6 \mathrm{ab}$ & $53.1 \mathrm{ab}$ & 19.06 \\
\hline 9 & $56.6 b$ & $46.9 b$ & 17.22 \\
\hline KK (\%) & 27.91 & 29.08 & $20.69^{1)}$ \\
\hline Interaksi & tn & tn & tn \\
\hline
\end{tabular}

Keterangan: Berdasarkan uji DMRT (Duncan multiple range test) taraf 5\%, angka yang disertai dengan huruf yang berbeda pada kolom yang sama menunjukkan berbeda nyata; $\mathrm{tn}=$ tidak nyata; ${ }^{1)}=$ hasil transformasi $\sqrt{ } \mathrm{x}+0.5 ;$ MSA $=$ minggu setelah antesis 
Hadisugelar et al. / J. Agron. Indonesia 48(2):180-186

Tabel 3. Produksi biji jintan hitam pada berbagai dosis asam humat dan waktu panen berbeda

\begin{tabular}{lcccc}
\hline Perlakuan & $\begin{array}{c}\text { Jumlah biji } \\
\text { per kapsul }\end{array}$ & $\begin{array}{c}\text { Bobot biji } \\
\text { per tanaman }(\mathrm{g})\end{array}$ & $\begin{array}{c}\text { Bobot 100 biji } \\
(\mathrm{g})\end{array}$ & $\begin{array}{c}\text { Produktivitas } \\
\left.(\mathrm{kg} \mathrm{ha})^{-1}\right)\end{array}$ \\
\hline Asam humat (ton ha $\left.{ }^{-1}\right)$ & & & & \\
Kontrol & 77.62 & $11.05 \mathrm{ab}$ & 0.23 & $661.32 \mathrm{a}$ \\
1.5 & 58.93 & $10.18 \mathrm{ab}$ & 0.24 & $541.83 \mathrm{ab}$ \\
3.0 & 76.05 & $12.38 \mathrm{a}$ & 0.23 & $555.80 \mathrm{a}$ \\
4.5 & 76.65 & $8.45 \mathrm{~b}$ & 0.22 & $334.55 \mathrm{~b}$ \\
Waktu panen (MSA) & & & 0.23 & 488.63 \\
6 & $77.62 \mathrm{a}$ & $11.60 \mathrm{a}$ & 0.23 & 537.85 \\
7 & $77.66 \mathrm{a}$ & $11.62 \mathrm{a}$ & 0.23 & 632.70 \\
8 & $78.78 \mathrm{a}$ & $10.78 \mathrm{ab}$ & 0.23 & 434.32 \\
9 & $70.19 \mathrm{~b}$ & $8.07 \mathrm{~b}$ & 5.71 & $25.63^{1)}$ \\
\hline KK $(\%)$ & 9.95 & $15.89^{1)}$ & $*$ & tn \\
\hline Interaksi & th & tn & & \\
\hline
\end{tabular}

Keterangan: Berdasarkan uji DMRT (Duncan multiple range test) taraf 5\%, angka yang disertai dengan huruf yang berbeda pada kolom yang sama menunjukkan berbeda nyata; $*=$ terdapat interaksi $\mathrm{tn}=$ tidak nyata; ${ }^{1)}=$ hasil transformasi $\sqrt{\mathrm{x}}+0.5 ; \mathrm{MSA}=$ minggu setelah antesis

Jumlah biji per kapsul, bobot biji pertanaman, dan produktivitas pada penelitian ini lebih tinggi dibanding penelitian sebelumnya khususnya di Indonesia tetapi untuk produktivitas lebih rendah dibanding di negara-negara asal penyebaran. Jumlah biji pada penelitian-penelitian sebelumnya sebesar 30.3 (Ridwan et al., 2014), 51.3 (Suryadi et al., 2014) sedangkan untuk bobot biji per tanaman pada penelitian sebelumnya mencapai $1.69 \mathrm{~g}$ (Mardisiwi et al., 2018), dan $1.1 \mathrm{~g}$ (Suryadi et al., 2014). Produksi biji jintan hitam di Iran mencapai 398-531.24 $\mathrm{g} \mathrm{ha}^{-1}$ (Aiyafar et al., 2015; Ariafar et al., 2017), Turki 192.2-940.3 $\mathrm{kg} \mathrm{ha}^{-1}$ (Kara et al., 2014), India 602-848 kg ha-1 (Giridhar et al., 2017).

Proses pengisian biji dipengaruhi oleh ketersediaan hara $\mathrm{K}$ dalam tanaman (Simanungkalit 2014). Pemberian asam humat yang berlebihan pada tanah atau melalui daun tanaman akan menghambat tanaman dalam menyerap kalium sehingga mengakibatkan terganggunya pembungaan dan pengisian biji atau buah (Khaled dan Fawy, 2011). Pemanfaatan asam humat dapat menstabilkan produksi tanaman jintan hitam (Safaei et al., 2014).
Pemanenan kapsul jintan hitam 9 MSAakan berdampak pada pengurangan jumlah biji pada kapsul tanaman yang akhirnya menurunkan bobot biji per tanaman. Hal ini diduga karena kapsul pada 9 MSA mulai pecah sehingga biji yang berada dalam folikel berpeluang akan keluar. Selain itu, semakin lama proses pemanenan kapsul memungkinkan serangan hama semakin tinggi. Kapsul jintan hitam telah dapat dipanen pada $6 \mathrm{MSA}$, dalam penelitian di Turki dilaporkan bahwa umur kematangan sempurna terjadi pada 7 MSA (Telci et al., 2014). Terdapat interaksi antara asam humat dan waktu panen berbeda terhadap bobot 100 biji jintan hitam. Pemberian asam humat 1.5 ton ha ${ }^{-1}$ dan waktu panen 6 MSA menghasilkan bobot 100 biji terbaik (Tabel 4).

\section{Kadar dan Produksi Timokuinon}

Pemberian asam humat dan waktu panen menunjukkan tidak berbeda nyata terhadap kadar dan produksi timokuinon serta tidak terdapat interaksi diantara keduanya (Tabel 5).

Tabel 4. Interaksi antara pemberian asam humat dan waktu panen berbeda terhadap bobot 100 biji

\begin{tabular}{lcccc}
\hline \multirow{2}{*}{ Asam humat ton $\mathrm{ha}^{-1}$} & \multicolumn{4}{c}{ Waktu panen (MSA) } \\
\cline { 2 - 5 } & 6 & 7 & $0.24 \mathrm{ab}$ & $0.23 \mathrm{ab}$ \\
\hline Kontrol & $0.23 \mathrm{~b}$ & $0.23 \mathrm{~b}$ & $0.23 \mathrm{~b}$ & $0.22 \mathrm{~b}$ \\
1.5 & $0.27 \mathrm{a}$ & $0.23 \mathrm{~b}$ & $0.22 \mathrm{~b}$ & $0.23 \mathrm{ab}$ \\
3.0 & $0.22 \mathrm{~b}$ & $0.22 \mathrm{~b}$ & $0.24 \mathrm{ab}$ & $0.24 \mathrm{ab}$ \\
4.5 & $0.22 \mathrm{~b}$ & $0.22 \mathrm{~b}$ & \\
\hline
\end{tabular}

Keterangan: Berdasarkan uji DMRT (Duncan multiple range test) taraf 5\%, angka yang disertai dengan huruf yang berbeda pada kolom yang sama menunjukkan berbeda nyata; $\mathrm{MSA}=$ minggu setelah antesis 
Waktu panen yang berbeda tidak bepengaruh nyata diduga karena tingkat kematangan dan pengisian biji telah maksimal sehingga kandungan timokuinon tidak berbeda diantara ketiga waktu panen. Kadar timokuinon penelitian ini lebih tinggi dari penelitian sebelumnya 2,459.56 $\mathrm{g} \mathrm{g} \mathrm{g}^{-1}$ (Herlina et al., 2017), tetapi lebih rendah dibandingkan dengan Al Asad (2019) dengan 6,734.26 $\mu \mathrm{g} \mathrm{g}^{-1}$.

Biji jintan hitam dengan tingkat kematangan yang berbeda mempengaruhi kandungan kimia jintan hitam (Telci et al., 2014). Beberapa pembuktian menunjukkan pengaruh tingkat kematangan buah terhadap kandungan bioaktif seperti kandungan asam lemak buah argan (Harhar et al., 2019), dan komposisi senyawa terpen tanaman duku dipengaruhi oleh tingkat kematangan yang berbeda (Sangkasanya et al., 2014). Komposisi kimia dalam tanaman obat dipengaruhi oleh kondisi klimatologi dan aksesi tanaman (Herlina et al., 2017).

Tabel 5. Kadar dan produksi timokuinon pada berbagai dosis asam humat dan waktu panen berbeda pada tanaman jintan hitam

\begin{tabular}{lcc}
\hline Perlakuan & $\begin{array}{c}\text { Kadar timokuinon } \\
\left(\mu \mathrm{g} \mathrm{g}^{-1} \mathrm{biji}\right)\end{array}$ & $\begin{array}{c}\text { Produksi timokuinon } \\
\left(\mathrm{mg} \mathrm{ha}^{-1}\right)\end{array}$ \\
\hline Asam humat ton $\mathrm{ha}^{-1}$ & $2,894.67$ & $2,435.57$ \\
$\quad$ Kontrol & $1,832.64$ & $1,486.26$ \\
1.5 & $2,740.78$ & $1,615.32$ \\
3.0 & $2,295.39$ & 827.11 \\
4.5 & $2,440.87$ & $1,591.07$ \\
Rataan & & $1,196.53$ \\
Waktu panen (MSA) & $2,429.60$ & $1,723.95$ \\
6 & $1,712.22$ & $1,181.94$ \\
7 & $2,423.88$ & $1,631.85$ \\
8 & $3,347.03$ & $1,591.07$ \\
9 & $2,479.11$ & $39.71^{1)}$ \\
\hline Rataan & $27.78^{1)}$ & tn \\
\hline Interaksi & tn & \\
\hline
\end{tabular}

Keterangan: Berdasarkan uji DMRT (Duncan multiple range test) taraf 5\%, angka yang disertai dengan huruf yang berbeda pada kolom yang sama menunjukkan berbeda nyata; $t \mathrm{tn}=$ tidak nyata; ${ }^{1}=$ hasil transformasi $\sqrt{ } \mathrm{x}+0.5$; MSA $=$ minggu setelah antesis

\section{KESIMPULAN}

Pemberian asam humat tidak berpengaruh terhadap produksi kapsul, biji, kadar dan produksi timokuinon, tetapi pemberian asam humat 4.5 ton $\mathrm{ha}^{-1}$ menurunkan produksi tanaman seperti jumlah kapsul total, jumlah kapsul isi, bobot biji per tanaman, dan produktivitas biji. Waktu panen berpengaruh terhadap produksi kapsul dan biji, pemanenan terbaik pada 6 sampai 7 MSA, tetapi tidak mempengaruhi kadar dan produksi timokuinon. Interaksi terjadi antara asam humat dan waktu panen pada bobot 100 biji dengan kombinasi terbaik pada dosis 1.5 ton $\mathrm{ha}^{-1}$ dan dipanen 6 MSA.

\section{UCAPAN TERIMA KASIH}

Terimakasih kepada Kementerian Riset dan Perguruan Tinggi atas pendanaan dalam program Penelitian Terapan Unggulan Perguruan Tinggi tahun 2019, dengan ketua Dr Ani Kurniawati, SP, M.Si.

\section{DAFTAR PUSTAKA}

Ahmad, A., A. Husain, M. Mujeeb, S.A. Khan, A.K. Najmi, N.A. Siddique, Z.A. Damanhouri, F. Anwar. 2013. A review on therapeutic potential of Nigella sativa: a miracle herb. Asian Pac. J. Trop. Biomed. 3:337352.

Aiyafar, S., H.M. Poudineh, M. Forouzandeh. 2015. Effect of humic acid on qualitative and quantitative characteristics and essential oil of black cumin (Nigella sativa L.) under water deficit stress. DAVIJS. 4:89-102.

AlAsad, F. 2019. Kajian pemanfaatan FMAdan pengurangan pupuk N, P untuk meningkatkan pertumbuhan, produksi, dan kadar metabolit jintan hitam (Nigella sativa L.). Tesis. Sekolah Pascasarjana. Institut Pertanian Bogor. Bogor. 
Ali, M.M.K., M.A. Hasan, M.R. Islam. 2015. Influence of fertilizer levels on the growth and yield of black cumin (Nigella sativa L.). The Agriculturists 13:97104.

Al-Saleh, I.A., G. Billedo, I.I. El-Doush. 2006. Level of selenium, tocopherol, thymoquinone and thymol of Nigella sativa seed. J. Food Compost. Anal. 19:167175.

Ariafar, S., M. Foouzandeh. 2017. Evaluation of humic acid application on biochemical composition and yield of black cumin under limited irrigation condition. Bull. Soc. Sci. Liege. 86:13-24.

De Melo, B.A.G., F.L. Motta, M. Helena, A. Santana. 2016. Humic acids: Structural properties and multiple functionalities for novel technological developments. Mater. Sci. Eng. C. 62:967-974.

Duda, S.C., L.A. Marghitas, D. Dezmirean, M. Duda, R. Madrgaoan, O. Bobis. 2015. Changes in major bioactive compounds with antioxidant activity of Agastache foeniculum, Lavandula angustifolia , Melissa officinalis and Nepeta cataria: Effect of harvest time and plant species. Ind. Crop. Prod. 77:499-507.

Gerige, S.J., M. Kumar, Y. Gerige, M. Rao. 2009. GC-MS analysis of Nigella sativa seeds and antimicrobial activity of its volatile oil. Braz. Arch. Biol. Technol. 52:1189-1192.

Giridhar, K., G.S. Reddy, S.S. Kumari, A.L. Kumari, A. Sivasankar. 2017. Influence of sowing window and plant density on growth, phenology, yield and quality of Nigella sativa L. in coastal humid tropic. Int. J. Curr. Microbiol. App. Sci. 6:499-512.

Harhar, H., S. Gharby, Y.E. Idris, D. Pioch, B. Mattahaus, Z. Charrouf, M. Tabayoui. 2019. Effect of maturity stage on the chemical composition of argan fruit pulp. OCL. 26:1-8.

Herlina. 2018. Adaptasi jintan hitam (Nigella sativa L.) dan produksi timokuinon dan timol biji di tiga ketinggian wilayah tropika Indonesia. Disertasi. Sekolah Pascasarjana. Institut Pertanian Bogor. Bogor.

Herlina., S.A. Aziz, A. Kurniawati, D.N. Faridah. 2017. Changes of thymoquinone, thymol, and malondialdehyde content of black cumin (Nigella sativa L.) in response to Indonesia tropical altitude variation. HAYATI. J. Biosci. 24:156-161.
Kara, N., D. Katar, H. Baydar. 2015. Yield and quality of black cumin (Nigella sativa L.) populations: the effect of ecological conditions. Turk. J. Field Crops 20:9-14.

Khaled, H., H.A. Fawy. 2011. Effect of different levels of humic acids on the nutrient content, plant growth, and soil properties under conditions of salinity. Soil Water Res. 6: 21-29.

Lin, J., C. Liu, Y. Chen, C. Hu, L. Juang, C. Shiesh, D. Yang. 2014. Chemical composition, antioxidant and anti-inflammatory properties for ethanolic extracts from Pleurotus eryngii fruiting bodies harvested at different time. LWT-Food Sci. Technol. 55:374-382.

Mardisiwi, R.S., A. Kurniawati, E. Sulistiyono, D.N. Faridah. 2018. Pertumbuhan dan produksi jintan hitam pada beberapa komposisi media tanam dan interval penyiraman. J. Agron. Indonesia 46:89-94.

Rabbani, M.A., A. Ghafoor, M.S. Masood. 2011. NARCkalonji : An early maturing and high yielding variety of Nigella sativa released for cultivation in Pakistan. Pak. J. Bot. 43:191-195.

Ridwan, T., M. Ghulamahdi, A. Kurniawati. 2014. Laju pertumbuhan dan produksi jintan hitam (Nigella sativa L.) dengan aplikasi pupuk kandang sapi dan fosfat alam. J. Agron. Indonesia 42:158-165.

Safaei, Z., M. Azizi, G. Davarynejad, H. Aroiee. 2014. The effect of foliar application of humic acid and nanofertilizer (pharmks $®)$ on yield and yield components of black cumin (Nigella sativa L.). JMPB. 2:133-140.

Sangkasanya, S., S. Lertsiri, M. Meenune. 2014. Changes in fruit quality and volatile flavor compounds during ontree maturation of longkong. IFRJ. 21:1659-1665.

Setiawati, E., A. Kurniawati, W.D. Widodo, D.N. Faridah. 2018. Pertumbuhan jintan hitam (Nigella sativa L.) pada tingkat naungan dan pemupukan nitrogen yang berbeda. J. Agron. Indonesia 46:202-207.

Simanungkalit, F.D., M.K. Bangun, I. Nuriadi. 2014. Respons pertumbuhan dan produksi beberapa varietas tanaman jagung (Zea mays L.) terhadap pemberian pupuk P dan K. J. Online Agroekoteknologi 2:813824.

Suryadi, R., M. Ghulamahdi, A. Kurniawati. 2015. Respon pertumbuhan dan produksi jintan hitam (Nigella sativa L.) dengan pemupukan nitrogen dan fosfor. J. Agron. Indonesia 43:227-234. 
Tavakkoli, A., H. Hosseinzadeh, V. Mahdian, B.M. Razavi. 2017. Review on clinical trials of black seed (Nigella sativa) and Its active constituent, thymoquinone. J. Pharmacopuncture 20:179-193.

Telci, I., A. Sahin-Yaglioglu, F. Eser, H. Aksit, I. Demirtas, S. Tekin. 2014. Comparison of seed oil composition of Nigella sativa L. and N. damascena L. during seed maturation stages. J. Am. Oil Chem. Soc. 91:17231729.
Tuncturk, R., M. Tuncturk, V. Ciftci. 2012. The effects of varying nitrogen doses on yield and some yield components of black cumin (Nigella Sativa L.). Adv. Environ. Biol. 6:855-858.

Zandonadi, D.B., L.P. Canellas, A.R Facanha. 2007. Indolacetic and humic acids induce lateral root development through a concerted plasmalemma and tonoplast $\mathrm{H}^{+}$pumps activation. Planta 225:15831595. 